\title{
Entre la política y la paz: las Fuerzas Militares tras la firma del Acuerdo de Paz
}

\section{Between Politics and Peace: the Military Forces After the Signing of the Peace Agreement}

\author{
Olga Illera ${ }^{1}$ \\ Universidad Militar Nueva Granada (Colombia) \\ Juan Carlos Ruiz ${ }^{2}$ \\ Universidad del Rosario (Colombia)
}

Recibido: 01-11-17

Aprobado: 02-02-18

\section{Resumen}

El artículo busca discutir las relaciones civiles-militares en Colombia en los escenarios de negociación y los desafíos que implica el Acuerdo de paz con las Fuerzas Armadas Revolucionarias de Colombia - FARC. Se lleva a cabo una caracterización histórica para entender el comportamiento de la institución militar en la vida política del país y presentar los momentos de tensión con los gobiernos, en particular con relación a los procesos de paz. La coyuntura actual colombiana muestra una mayor visibilidad de las tensiones para las Fuerzas Militares que se encuentran en medio del debate de la política y la paz.

Palabras-clave: Fuerzas Militares Colombia, relaciones civiles-militares, proceso de paz.

\footnotetext{
${ }^{1}$ (olga.illera@unimilitar.edu.co). Máster en Estudios Latinoamericanos de la Universidad de Oxford y Decana de la Facultad de Relaciones Internacionales, Estrategia y Seguridad de la Universidad Militar Nueva Granada, Colombia.

2 (juan.ruiz@urosario.edu.co). Doctor en Ciencia Política de la Universidad de Oxford y Profesor Titular de la Facultad de Ciencia Política, Gobierno y Relaciones Internacionales de la Universidad del Rosario, Colombia.
} 


\begin{abstract}
The article seeks to discuss the military civil relations in Colombia in the negotiation scenarios and the challenges implied by the Peace Agreement with the Revolutionary Armed Forces of Colombia-FARC. A historical characterization is presented to understand the behavior of the military institution in the political life of the country and present the moments of tension with the governments, in particular in relation to the peace processes. The Colombian situation shows a greater visibility of tensions for the Military Forces that are in the middle of the debate on politics and peace.
\end{abstract}

Key-words: Colombian Military Forces, Civil Military Relations, Peace Process.

\title{
1. Introducción
}

Colombia ha sido una excepción regional en la configuración de las relaciones civiles-militares debido al predominio de partidos políticos históricamente fuertes, que ayudaron a la configuración de unas fuerzas militares y policiales subordinadas al poder político. Las irrupciones militares en política en Colombia, por tanto, han sido limitadas a un breve gobierno semi-militar, algunos "ruidos de sables" o expresiones públicas de inconformidad por parte de altos mando y a un par de planes de intervenciones militares pobremente organizadas y ejecutadas ${ }^{3}$. Sin embargo, la estabilidad de la interacción civil militar en Colombia ha tenido como puntos álgidos y de tensión los procesos de negociación del conflicto armado.

Este artículo buscará discutir las relaciones civiles-militares en los escenarios de negociación y posconflicto. En una primera sección se presenta una aproximación histórica a las relaciones civiles-militares en Colombia. En la segunda sección se hace un recuento de algunas de las tensiones entre militares y políticos en el contexto de negociación. En tercer lugar, se hará un breve balance de las interacciones civiles militares en el proceso de paz de $\mathrm{La}$ Habana. Finalmente, se plantean algunos retos de las Fuerzas Armadas en el posconflicto.

Se tendrán en cuenta dos variables de la discusión de las relaciones civiles militares: la primera de ellas es la relativa al control político, es decir, la capacidad del presidente en su calidad de Comandante en Jefe de las Fuerzas

\footnotetext{
3 En mayo 2 de 1958 se dio un intento febril de organizar un golpe de Estado, liderado por el coronel Hernando Forero Gómez. En octubre 1961 se malogra una acción conspirativa del Teniente Cendales, ninguno de los planes constituía un verdadero riesgo y fueron consideradas expresiones facciones nostálgicas al interior de las Fuerzas Armadas. (Pizarro 1995: 164).
} 
Militares de tomar decisiones como remoción, promoción de los altos mandos militares y la capacidad del Presidente de establecer las prioridades en materia de seguridad. La segunda variable es la participación política de los militares, pues en Colombia los militares no pueden votar ni deliberar, si bien encuentran mecanismos para manifestar sus posiciones frente a temáticas como los actores armados ilegales e incluso el manejo de las relaciones internacionales.

\section{La excepcionalidad colombiana: del control de los partidos y el conflicto interno armado}

En América Latina, Colombia se destaca como un país de escasas intervenciones militares en la política. Desde su independencia, ha experimentado dos gobiernos militares de corta duración. El Gobierno militar de Rojas Pinilla fue un experimento que contó con el respaldo y participación de segmentos sustanciales del Partido Conservador, y con la aprobación de diferentes líderes del Partido Liberal. Esta intervención militar tenía como objeto poner punto final al Gobierno conservador de Laureano Gómez, y la inestabilidad y violencia que se incrementó bajo su gestión. (Hartlyn 1984: 249) Tanto, que el Presidente Gómez percibió la inconveniencia de la presencia del General Rojas como Comandante General de las Fuerzas Militares, razón por la cual pediría su renuncia en junio de 1953.

Este hecho fue el catalizador de la toma del poder por parte de los militares en Colombia quienes, finalmente, decidieron participar en un golpe de estado. (Leal 1970: 512 y Pizarro 1989: 8). Rojas trató de reducir la polarización política y asegurar la participación de los dos partidos políticos en el Gobierno, de manera tal que incluso esta intención de permitir a los partidos políticos tradicionales conservar parte del control en el Estado mantuvo, más o menos limitada, la participación de oficiales de las Fuerzas Militares en el aparato estatal (Atehortúa, 2010: 39).

Los líderes de los partidos Conservador y Liberal concebían el régimen militar como una interrupción transitoria, cuya finalidad era la reducción de la violencia política. En sus planes no estaba la idea de un Gobierno que les ofreciera competencia en materia de representación política, de modo que, por eso, ciertas medidas adoptadas por Rojas Pinilla, orientadas a la construcción de un proyecto electoral independiente de los partidos tradicionales, una especie de "Tercera Fuerza" generó descontento en los partidos políticos y en algunos sectores de las Fuerzas Militares. Ello, por considerar que los militares no debían tener un rol protagónico en la vida política nacional y tenían que centrarse exclusivamente en proteger los intereses del Estado y alejarse del Gobierno (Premo 1992: 103). 
Los líderes de los liberales y conservadores iniciaron así conversaciones para la restitución del control partidista del poder La oposición al régimen de Rojas se fortaleció, convocando a los partidos políticos, la Iglesia, los gremios y sectores militares, lo cual conduce a la conformación de una Junta Militar de transición en mayo de 1957. Los partidos establecen de ese modo un pacto conocido como Frente Nacional, por el cual se establecía la alternancia en el poder y el reparto equitativo de cargos públicos entre los dos partidos hegemónicos, por un período de 16 años. La intervención militar, por ende, terminó siendo más un mecanismo de estabilización auspiciada desde los mismos partidos políticos tradicionales, que una toma del poder por parte del estamento militar.

El referido Frente Nacional inicia con Alberto Lleras Camargo, el 15 de mayo de 1957, quien protagoniza un discurso ante las Fuerzas Militares en el Teatro Patria de Bogotá, en el que se establecen los lineamientos para las relaciones políticos-militares en Colombia. En este se expresaba:

"La política es el arte de la controversia por excelencia. La milicia, el de la disciplina. Cuando las Fuerzas Armadas entran a la política, lo primero que se quebranta es su unidad porque abre la controversia en sus filas. El mantenerlas apartadas de la deliberación pública no es un capricho de la Constitución, sino una necesidad de su función. Si entran a deliberar entran armadas" (Lleras Camargo, 1957).

Este discurso se asume como el "gran contrato de recíproco respeto entre el Gobierno y las Fuerzas Militares", de forma tal que el Presidente reiteraba su autoridad sobre el poder militar, reconociéndole a los militares un grado de autonomía en cuanto al manejo de sus asuntos internos. (Velásquez 1999: 4) Esta división entre la política y los asuntos internos de las Fuerzas Armadas ha sido, desde entonces y para muchos, uno de los elementos para la estabilidad y consistencia de las relaciones entre militares y políticos.

Los cuestionamientos a la autoridad presidencial por parte de los militares y las tensiones en su interacción no produjeron entonces momentos de tensión significativos. El patrón que se estableció, y que se mostraba como un remanente histórico en la interacción civil-militar en Colombia, era el del ejercicio de la autoridad política para remover del cargo a aquellos oficiales que se consideraban problemáticos o que se manifestaban en abierto desacuerdo con los lineamientos del Gobierno. El conflicto armado interno por su parte generaba espacios importantes para la participación de los militares en la vida pública nacional, además de un amplio margen de actividad en lo operativo, social y financiero. Para Vargas, esto, adicionalmente, puede reflejar un divorcio de funciones, al hacer referencia a la despreocupación de los líderes civiles frente a los temas de seguridad y defensa. (Vargas 2003: 84) 
El rol de las Fuerzas Militares, por tanto, desde finales de los cincuenta y principios de los sesenta, se concentró en el mantenimiento de la seguridad del régimen democrático a través del control del orden público (Pizarro 1990: 427). La situación de seguridad interna, especialmente a través de la figura del estado de sitio, le permitió a los militares retener un grado importante de participación en los asuntos públicos. Los militares obtenían el derecho de jurisdicción sobre los civiles, aunque el grado de efectividad y uso de este tipo de atribuciones fue diferencial en los municipios del país.

El deterioro de las condiciones de seguridad interna y el aumento de la protesta social llevaron a que, en 1978, el Presidente Julio Cesar Turbay Ayala promulgara el Decreto Legislativo 1923, más conocido como el Estatuto de Seguridad. Este documento resumió las leyes previas contra la subversión y buscaba aumentar el control de la fuerza pública frente al conflicto armado, lo que llevó a la contención violenta de la protesta social, y en particular de la actuación de los sindicatos (Torres, 2000).

A ello se sumará la lucha contrainsurgente, que comienza formalmente desde mediados de los sesenta, y que se intensifica a finales de los setenta (Ríos, 2017), dejando consigo una importante afectación a los valores, comportamientos y mentalidad de la institución militar. Así, el respeto a las normas constitucionales pasa a reforzarse con la figura de un enemigo común entre políticos y militares. (Pizarro 1989: 12). Es decir, confrontar las guerrillas va a permitir una coincidencia de intereses que conferirá estabilidad a la interacción civil-militar, y en contraste a las tensiones surgidas bajo los escenarios de negociación política ${ }^{4}$.

\section{Los procesos de paz y las tensiones civiles-militares en Colombia}

La tensión de las relaciones civiles-militares ha estado centrada mayormente en el sentimiento de que las Fuerzas Militares no eran consultadas en las negociaciones de paz. Mientras que el tratamiento del conflicto armado sí era considerado un asunto militar, los asuntos de la estrategia de paz se consideraban como un aspecto restringido únicamente a los políticos. Esta situación ha generado algunas demostraciones de descontento, de forma casi que recurrente en todos los procesos.

\footnotetext{
${ }^{4}$ Para Vargas, el tema de las negociaciones de paz ejemplifica la tensión entre los políticosgobernantes-negociadores y las fuerzas militares. "Tenemos una desconfianza mutua entre civiles y militares, y este es el peor de los mundos. La guerra y la paz son las dos caras de un mismo problema y no es posible una estrategia adecuada para enfrentarlo, sin abordarlo de manera coordinan las dos dimensiones. Hay que conocer de manera clara las estrategias del adversario y cómo van evolucionando las mismas, para poder dar las respuestas pertinentes.” (Vargas 2003: 85)
} 
Desde inicios de los setenta, bajo la presidencia de Misael Pastrana, el Ejército había desarrollado una estrategia para eliminar al Ejército de Liberación Nacional - ELN, de modo que, desde la perspectiva operativa, la eventual derrota insurgente resultaba un hecho plausible. Un hecho, sin embargo, truncado cuando su sucesor, el Gobierno de López Michelsen, propuso sensu contrario una aproximación política para negociar su rendición. En ese momento, el comandante del Ejército, el General Álvaro Valencia Trovar, trató de disuadir al Gobierno expresando que la guerrilla no tenía intenciones reales de hacer la paz, y que, por el contrario, aceptar una propuesta política le daría tiempo de salvar el impasse militar. Este hecho desencadenaría la petición de su retiro (Valencia, 1992: 635).

Durante el Gobierno de Belisario Betancur, entre 1982 y 1986, se hizo una oferta de amnistía a las guerrillas, incluyendo a los miembros de la guerrilla del M-19 capturados durante el periodo de gobierno de Turbay ${ }^{5}$. Esta oferta de paz, así como las reuniones sostenidas con miembros de las FARC generaron tensiones con la cúpula militar, pues aún consideraban viable la rendición a través de la estricta acción militar. De hecho, el Alto Comando publicitó en medios de comunicación sus ideas sobre seguridad, política exterior y otros temas, que no necesariamente eran de su resorte, pero en los cuales el sector militar tenía un concepto, en ocasiones, muy diferente al sostenido por los líderes políticos del momento. El presidente respondería a ello con un discurso muy similar al de Lleras Camargo de 1958, reiterando de esta manera la división de esferas entre lo político y lo militar y la importancia de la supremacía civil. Incluso, llegó a solicitar el retiro del Ministro de Defensa, el General Ladazábal, y algunos generales que habían participado en estas discusiones.

La solicitud del retiro de parte de la cúpula generó malestar al interior de las Fuerzas Militares. Esta fisura se evidenciaría en noviembre de 1985, cuando la guerrilla del M-19 tomó el Palacio de Justicia durante dos días. La recuperación del Palacio por parte de los militares terminó siendo muy cuestionada, hasta el punto de que algunos llegaron a referirse a un golpe militar de facto (Sánchez 2010: 106). Por ejemplo, en declaración a la Comisión de la Verdad, el mismo expresidente Betancur llegaría a afirmar: "no ordené el ingreso de los tanques, la responsabilidad es del Comandante Militar. [...] Entregué el mando al Ejército como Comandante en Jefe" (Gómez 2010: 82; Revista Semana, 2006).

La seguridad en el país continuó deteriorándose durante la presidencia de Virgilio Barco (1986-1990), por lo que en este Gobierno también se alternó la confrontación con la iniciativa de negociación. En 1988, el Ministro de Defensa, el General Rafael Samudio Molina, renunciaría después de criticar abiertamente el proceso de paz y la aproximación política que se le estaba dando

5 "Ley 35. 1982. Por la cual se decreta una amnistía y se dictan normas tendientes al restablecimiento y preservación de la paz"

Araucaria. Revista Iberoamericana de Filosofía, Política y Humanidades, año 20, n 39. Primer semestre de 2018. Pp. 509-533. ISSN 1575-6823 e-ISSN 2340-2199 doi: 10.12795/araucaria.2018.i39.24 
al manejo de las guerrillas. Incluso, cuando de forma paralela, el Gobierno de Barco lograba un acuerdo de paz exitoso con el M-19. El Presidente introdujo a civiles a posiciones importantes relacionadas con la seguridad, y Rafael Pardo Rueda fue nombrado al frente de la Consejería Presidencial de Reconciliación, toda vez que Ernesto Peña era nombrado como Secretario General del Ministerio de Defensa. Así, se ponía en marcha un proceso con el que buscar un mayor involucramiento de los civiles en las áreas de seguridad, el cual va a tener continuidad con la presidencia de César Gaviria, quien designará por primera vez a civiles, tanto al frente del Ministerio de Defensa, como al frente de la Inteligencia, organizada en el Departamento Administrativo de Seguridad - DAS ${ }^{6}$ (Leal 1994: 127-134)

Estos cambios vinieron acompañados de un crecimiento del presupuesto militar y mejoras en las condiciones de las tropas, gracias a que en los cuatro años de gobierno de Gaviria el presupuesto militar se incrementó un 42\%. (González y Posada 2001:85). Para esta década, por ejemplo, la tasa de militares por 1.000 habitantes se incrementó en casi tres puntos, superando así la tendencia histórica del país, si bien, en todo caso, por debajo de la media regional. El esfuerzo en materia de seguridad llevaría, en cualquier caso, a conseguir, una cifra nada desdeñable, cercana a los 200.000 militares y 160.000 policías (Dávila 1997:6). A la par de lo anterior, se establecía un diálogo infructuoso con las FARC y el ELN en Caracas (Venezuela) y Tlaxcala (México), se adelantaron acercamientos con el EPL, PRT y la guerrilla indigenista Quintín Lame. Esto es, política de negociación con algunas guerrillas, unido a un sometimiento a la justicia de los carteles de droga y una confrontación directa con las FARC y el ELN (Ríos, 2017).

Durante el Gobierno de Ernesto Samper, transcurrido entre 1994 y 1998, las relaciones civiles-militares fueron difíciles, pues el Gobierno se encontraba fuertemente debilitado por las acusaciones de financiamiento del narcotráfico provenientes del cártel de Cali. Así, las críticas del Comandante del Ejército, el General Harold Bedoya, fueron públicas, cuestionando al Presidente, de modo que se generaría una importante fricción que estará vigente todo el período presidencial. Se llegó incluso a hablar de un posible golpe de estado orquestado por una alianza militar-civil que buscaría enfrentar lo que se entendía como un Gobierno ilegítimo (Vargas 2002: 213). Todo lo anterior, en un contexto en el que la FARC, y en menor medida el ELN, se mostraban fortalecidas, consiguiendo incluso importantes victorias militares frente al Ejército colombiano.

La presidencia de Andrés Pastrana (1998-2002) estuvo marcada por dos procesos muy significativos: los diálogos de paz con las FARC y las políticas de fortalecimiento militar. Desde el proceso electoral se establece la búsqueda de una salida negociada al conflicto como una prioridad para el país. Este

\footnotetext{
${ }^{6}$ Rafael Pardo Rueda es nombrado en agosto de 1991
} 
proceso dejaría consigo la creación de una zona desmilitarizada dentro de la cual se van a dar los diálogos ${ }^{7}$. Esta situación generará generó una gran tensión con los militares, descontentos por no haber sido consultados al respecto. No obstante, van a aconsejar al Presidente la necesidad de preservar la presencia de las autoridades civiles y el establecimiento de un calendario con fechas límites para el fin de proceso de desmilitarización, si bien estas ideas nunca fueron tomadas en cuenta. Esta tensión se agudizaría con la renuncia del ministro de Defensa, Rodrigo Lloreda, en mayo de 1999. Esto, por diferencias con el Presidente respecto a la negociación de paz (Fernández de Soto 2002: 146), y a lo que se sumaría le dimisión en bloque de la cúpula militar, poniendo así de manifiesto su descontento con el tratamiento del Presidente a las Fuerzas Militares en el marco del proceso de negociación (Revista Semana, 1999).

Quizás, por estar lo anterior muy relacionado con las tensiones militares, el Gobierno de Pastrana, e paralelo a lo descrito, inicia un proceso importante de fortalecimiento de la capacidad militar (Ríos 2015). En cierto sentido, esto le permitiría asumir una posición más fuerte en lo militar dentro de la mesa de negociación, abriendo así las perspectivas ante el poco avance de los diálogos y preparándose a efectos de una posible ofensiva militar contra la guerrilla. He aquí donde surge, por ejemplo, el Plan Colombia que, si bien inicia como una estrategia para la lucha antinarcóticos, permitirá un mejor equipamiento y fortalecimiento de las capacidades militares en su lucha contra las distintas insurgencias.

Tras el fracaso de las negociaciones del Caguán, es que se incrementa el apoyo de la opinión pública de una aproximación más militar que política, con la que superar el conflicto armado. De esta manera, los gobiernos de Álvaro Uribe Vélez (2002-2006; 2006-2010), a través de la Política de Seguridad Democrática, van poner en valor la posición más agresiva y beligerante contra las guerrillas de las últimas décadas (Leal 2006). Sea como fuere, se establecen negociaciones con el grupo paramilitar de las Autodefensas Unidas de Colombia, AUC, abriendo el debate de los nexos históricos de algunos militares con estos grupos, lo cual va a producir un importante menoscabo de la imagen de las Fuerzas Militares, tanto en Colombia como en el exterior (Avilés, 2006, 133-139). Ello, no solo por sus vínculos particulares con algunos grupos paramilitares en ciertas zonas del país, sino por su cuestionamiento a raíz del conocimiento de varias violaciones a los derechos humanos, y en particular a procesos de ejecuciones extrajudiciales y desapariciones forzadas (Angarita 2011: 292-298).

Es en este contexto que asume la presidencia Juan Manuel Santos, en el año 2010, y tras haber ejercido como Ministro de Defensa en el periodo 2006-

\footnotetext{
${ }^{7}$ La zona de distensión o de despeje tuvo una extensión de 47.000 kilómetros cuadrados y abarcaba los municipios de Mesetas, La Uribe, La Macarena, Villahermosa y San Vicente del Caguán,
} 
2009; tiempo en el cual se consiguieron importante éxitos operacionales en contra de las guerrillas ${ }^{8}$. En el proceso electoral se planteó la continuidad de la política de seguridad desarrollada bajo el gobierno predecesor, lo cual así parecía a tenor del abatimiento de dos de los líderes históricos de la guerrilla como "Mono Jojoy" (2010) o "Alfonso Cano" (2011). Sin embargo, mientras esto sucedía, en paralelo se realizaban acercamientos para el establecimiento de diálogos con las FARC, los cuales se formalizarán de manera pública en octubre de 2012.

\section{Los militares y el actual proceso de paz: caminando en una cuerda floja}

El actual proceso de paz ha sido el escenario más político y debatido en el que han participado los militares en más de sesenta años de historia colombiana, lo cual, también ha hecho más visibles las tensiones existentes.

Dos elementos han cambiado muy sustancialmente desde el contexto de negociación de Pastrana al actual de Santos. Las Fuerzas Militares difieren mucho en tamaño, capacidad y organización, y mientras la primera negociación se estableció tras una serie de derrotas militares, la presidencia de Juan Manuel Santos se daba tras importantes golpes a las estructuras guerrilleras (Ríos, 2017). Algo que refuerza la idea de los militares respecto de la cual, era viable sostener una estrategia de confrontación y, por ende, afligir una derrota militar a la guerrilla.

Las Fuerzas Militares colombianas son hoy día un cuerpo mejor equipado y de dimensiones considerables. En 2017 llegaban a 369.100 miembros, 1o cual sitúa a Colombia muy por encima de vecinos regionales como México y Brasil, que son los países de mayor población en América Latina. La tasa de soldados por 100.000 habitantes en Colombia es de 781, mientras que países como Estados Unidos tienen tasas de 424, Francia 305 o Rusia con 560 (Global Fire Power Index 2017).

\footnotetext{
${ }^{8}$ Acciones como la Operación Fénix (marzo 2008) que lleva a la muerte de Rául Reyes, miembro del secretariado de las FARC; en la zona de Angostura territorio ecuatoriano, Jaque (julio 2008) que permite la liberación de 15 secuestrados entre los que se encontraba la candidata presidencial Ingrid Betancourt y los tres contratistas militares estadounidenses.
} 


\section{Gráfico 1: Las FF.MM más grandes del mundo, 2017}

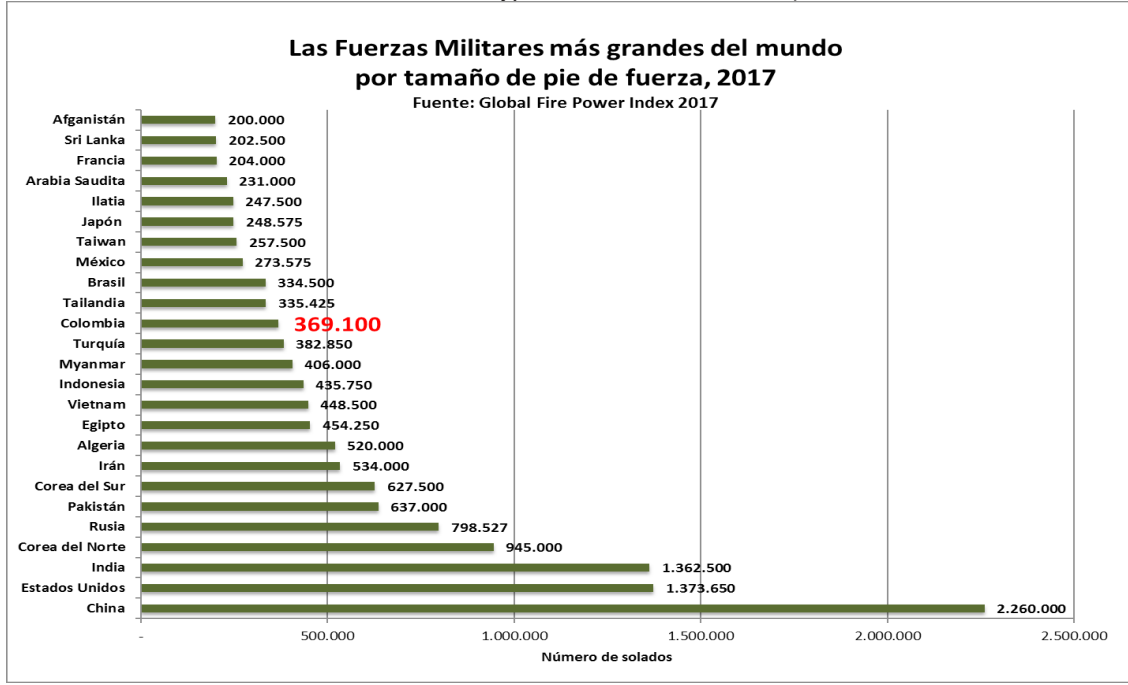

Fuente: Global Fire Power Index, 2017.

Gráfico 2: Tamaño de las FF.MM en América Latina y el Caribe, 2017

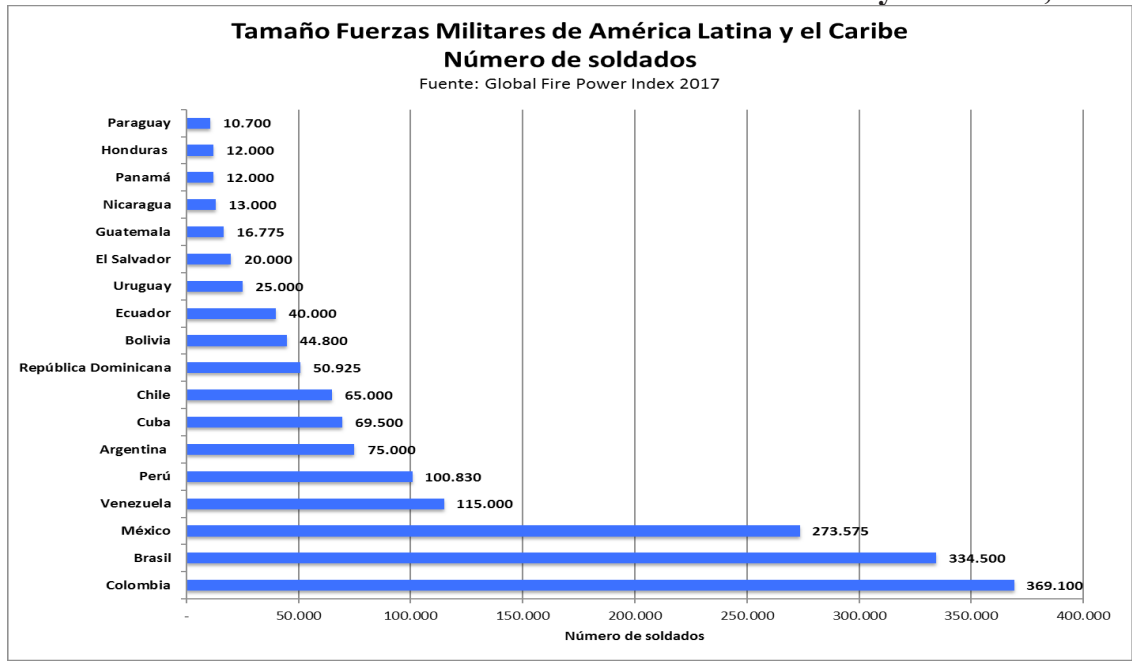

Fuente: Global Fire Power Index, 2017. 
Asimismo, estas Fuerzas Militares no sólo han crecido en tamaño y equipamiento, sino que también lo han hecho en recursos ${ }^{9}$, lo cual se explica por el conflicto armado interno y la simultaneidad de amenazas en forma de guerrillas, paramilitarismo, bandas criminales, carteles del narcotráfico y otras dinámicas de inseguridad.

El tema de la paz se convierte así en un elemento de división entre Santos y el expresidente Álvaro Uribe quien, para las elecciones de Congreso de la República, en 2013, decidió liderar la oposición con un partido de nueva creación llamado Centro Democrático. Esta fractura se percibe también en las Fuerzas Militares, en donde algunos consideran que negociar cuando se veía viable una derrota militar de las guerrillas se trata de un importante error (Torrijos 2017).

En cualquier caso, el modelo de la negociación con las FARC incluyó la participación de miembros de las Fuerzas Militares en servicio activo y en retiro, buscando con esto reducir el nivel de desconfianza de los militares y policías. Se vinculan de esta manera dos generales en retiro, en calidad de negociadores, a partir de octubre de 2012. Por un lado, el general Jorge Enrique Mora Rangel, quien había sido Comandante de las Fuerzas Militares en el 2002 bajo la presidencia de Uribe, además de Comandante del Ejército entre 1998 y 2002, durante el proceso de paz del presidente Pastrana. La Policía estuvo representada a su vez por el general Oscar Naranjo, director de la institución entre 2007 y 2012. Estas dos figuras se habían destacado por los resultados en la confrontación en contra de las guerrillas y gozaban de reconocimiento por parte de los militares activos y en retiro.

La participación de los militares en el proceso de negociación se refuerza en agosto de 20141 con la vinculación de personal en servicio activo, para la discusión de un modelo técnico de cese al fuego y de hostilidades bilateral, los aspectos operativos y técnicos para la dejación de las armas y desmovilización. El grupo era liderado por el general Javier Flórez, Jefe del Estado Mayor Conjunto y Subcomandante de las Fuerzas Militares ${ }^{10}$, hacía parte de la subcomisión técnica para temas de desarme, y de forma paralela se desempeñaba como jefe del Comando Estratégico de Transición de las Fuerzas Militares (COET).

Si bien el proceso de negociación de La Habana fue el primero en incorporar a las Fuerzas Militares dentro de las discusiones, la polarización y diferencias no se han reducido por ello. Todo lo contrario, la relevancia sin precedentes de las Fuerzas Militares en la vida política del país ha redundado en un nivel mayor de expresión de sus posiciones ante la opinión pública. Si bien procuran

\footnotetext{
${ }^{9}$ Para el año 2016 el gasto militar sobre el gasto total del gobierno era de $11.8 \%$, en contraste con países como Brasil con una tasa de 3.1\%, México 2.3\%, El Salvador 3,9\% o Chile en donde llega al 7.1\%. (SIPRI, 2017)

${ }^{10}$ El grupo estaba compuesto además por dos coroneles del Ejército, un teniente coronel de la Policía, un capitán de fragata, una teniente de navío y un mayor de la Fuerza Aérea.
} 
mantener el principio de la no deliberancia o involucramiento en política, su articulación con sectores de la oposición y la participación de militares en retiro en estas discusiones han dado a conocer las principales tensiones con respecto al proceso de paz. Para el Gobierno, mantener las negociaciones en medio del conflicto y mantener su interacción con las Fuerzas Militares ha redundado en un ejercicio de equilibrismo en la cuerda floja.

Por ejemplo, en el año 2014 se reveló la existencia de un andamiaje de espionaje telefónico e informático a través del cual civiles y militares se dedicaban a escuchar de manera ilegal a los miembros del equipo negociador del Gobierno. (Restrepo, 2014). Se hizo público que la Central de Inteligencia Militar, CIME, tenía información y correos personales de funcionarios relacionados con el proceso de paz, y se anunció una exhaustiva investigación, si bien, el resultado arrojado por la auditoría interna fue que no se encontraron dichos correos. El Ministerio de Defensa estableció un comité de alto nivel para investigar el tema de las interceptaciones, quienes concluyeron que se habían presentado debilidades en el manejo de seguridad informática y gestión documental. Así, se dio el relevo de una veintena de altos miembros de la Fuerza Pública y el retiro definitivo de otros cinco. El hacker Andrés Sepúlveda, en un preacuerdo con la Fiscalía, terminaría informando que el espionaje iba orientado a brindar información del proceso de paz a la oposición.

La participación de militares activos y en retiro en las negociaciones ha causado una polémica no vista con anterioridad. Fue percibido como una acción "humillante", de acuerdo con el senador Alfredo Rangel, y hasta calificada de "ilegal" por el expresidente Uribe, quien consideró que vincular militares activos en la negociación equivalí a poner a las Fuerzas Militares en el mismo nivel de la guerrilla (Revista Semana, 2014 b). De igual manera, también parte de los sectores en retiro terminaron manifestando de forma pública sus afinidades políticas ${ }^{11}$, de modo que en la campaña electoral de 2014 el Cuerpo de Generales y Almirantes en retiro, ACORE, se adhirió públicamente a la campaña de Oscar Iván Zuluaga, candidato uribista del Centro Democrático. Este partido buscó canalizar apoyos de los retirados incluyendo en sus listas a familiares de algunas de las más conocidas figuras militares. Así, en el contexto del debate político y electoral se cuestionó públicamente al mismo Gobierno por considerar que se había conducido a las Fuerzas Militares a una parálisis organizacional, al haberse reducido sus operaciones y, por ende, minar la moral de las tropas. En plena campaña electoral, el candidato del uribismo afirmaría,

${ }^{11}$ En el 20 de abril de 2015 en la Carrera de los Héroes 10k, el discurso del presidente fue acompañado de silbidos del público; días antes las FARC habían atacado a un grupo de militares produciendo 11 muertos, el público hacia manifiesto su descontento. Estos desordenes debieron ser controlados por el entonces Ministro de Defensa, Juan Carlos Pinzón quien dijo: "Gústele a quien le guste, las Fuerzas Armadas tienen un comandante en jefe y ese es el presidente, no silben más". (Revista Semana, 2015 b) en un intento por dar continuidad al evento y reafirmar la subordinación de los militares a la autoridad civil. 
por ejemplo, que: "nuestros militares están desmotivados, pues tenemos un gobierno complaciente con el terrorismo, que ha estado de espaldas a los sectores sociales y que no ha tenido liderazgo político para nuevamente tener una tropa con moral que vaya la ofensiva" (Neira, 2014).

De acuerdo al Sistema de Información del Centro de Operaciones del Ejército (SICOE), la desaceleración de la ofensiva militar más bien es resultado, incluso, de antes del inicio del proceso de paz de 2012. El punto más alto de la ofensiva militar es en el 2005 con 977 operativos. Para el año 2006 fueron 720 los operativos militares puestos en marcha, y a partir de 2007 se da una disminución notable con 378 acciones; 306 en el año siguiente y 203 para el 2009. El Gobierno de Álvaro Uribe terminará con 190 acciones de ofensiva militar contrainsurgente en 2010. De esta manera, en el año 2012, ya bajo el proceso de negociación exploratoria con las FARC, se dieron 163 operativos militares, seguidos de 111 y 103 en 2013 y 2014, respectivamente (Revista Semana, 2015a).

Si se compara pues, la información estadística recién descrita es que se podría concluir que con respecto al año 2005, paulatinamente, la ofensiva militar se había venido reduciendo significativamente, casi hasta un 90\%. Sin embargo, otras variables como presupuesto, tamaño y equipamiento mantuvieron su crecimiento de modo que el menor número de acciones militares no trajo consigo un deterioro de las condiciones de las Fuerzas Militares, ni nada parecido.

\section{La Paz firmada: ¿seguridad y reformas anheladas?}

El Gobierno de Juan Manuel Santos logró firmar el Acuerdo de la Habana con las FARC, no sin un traspié, al someter el documento a plebiscito nacional, el 2 de octubre de 2016, y gana el voto por la no con un 50.2\% sobre el escrutinio de participación, lo cual comprometía la refrendación del acuerdo. Esto suscita una serie de negociaciones con los partidos de la oposición para poder hacer ajustes y reiterar el proceso de firma definitiva con la guerrilla de las FARC. La polarización política derivada de lo anterior se ha reflejado en la dificultad para avanzar en la fase de implementación que actualmente transcurre.

Curiosamente los aspectos militares derivados del Acuerdo, tales como desmovilización, concentración y desarme, han sido durante el primer año de vigencia del Acuerdo los aspectos más fáciles de desarrollar, en particular, si se compara con las dimensiones políticas, la implementación normativa, la búsqueda de recursos y el hecho de transformar el Acuerdo final en un pacto suscrito en representación del Estado colombiano y no de un gobierno particular. En materia de relaciones civiles-militares hay tres temas que resultan 
esenciales: la Justicia Especial para la Paz - JEP, la reforma del sector Defensa y el nuevo contexto de seguridad y nuevas amenazas.

Dos temas han sido esenciales en el debate de la "seguridad jurídica" de las Fuerzas Militares. Por un lado, la justicia transicional en sí, y por el otro, el fuero militar. En materia de justicia transicional, el tema es muy sensible para las Fuerzas Militares, y en particular para los militares en retiro. Durante las negociaciones hubo reiterada preocupación por si los militares serían amparados por un régimen jurídico especial en el momento posterior al Acuerdo o si no (Revista Semana, 2014a) Una circunstancia ésta, que llevó a Presidente, ministros, negociadores y Fiscal General de la Nación, a reiterar que el modelo de justicia transicional cobijaba tanto a los guerrilleros como a los miembros de las Fuerzas Militares involucrados por razones derivadas del conflicto armado (Revista Semana, 2014 b, 2015 c, Zuleta, 2015).

En noviembre de 2016, se llevó a cabo una reunión con los representantes de 17 de las organizaciones de militares en retiro, para ratificar el Acuerdo con respecto al sistema de justicia transicional diseñado en el marco del proceso de la Habana (ACORE 2016). De dicha reunión se suponía un apoyo general al esquema presentado en el marco de la negociación, si bien, una vez se dieron los procesos de implementación, se presentaron inquietudes cada vez más fuertes. Se ha llegado a manifestar, por parte de militares en retiro, que estos tipos de espacios generan la oportunidad para persecuciones y venganzas contra los uniformados por la vía judicial (El Colombiano, 2017). Incluso, se integró una mesa permanente de trabajo con el fin de analizar el impacto de la "guerra jurídica" que presuponía la entrada en vigor de la jurisdicción especial; la cual era considerada como una concesión diseñada a la medida de las FARC (MTP Cuerpo de oficiales RA, 2017)

El primero de marzo de 2017, 20 de los más destacados generales, excomandantes de las Fuerzas Militares y de Policía, incluyendo al general Mora Rangel, remitieron una carta al Presidente, expresando sus inquietudes frente a la justicia transicional, la justicia penal militar y la jurisdicción internacional. Al tiempo, presentaban una proposición para que el Senado aclarasen dudas que se habían presentado frente a estos temas, buscando modificar contenidos del capítulo VII en relación con el tratamiento especial diferenciado para los miembros de la Fuerza Pública y que identificaba las conductas punibles sometidas a esta jurisdicción Cuellar, 2017). Le expresaban igualmente al Presidente su preocupación por la presencia de dos miembros del comité de escogencia de la Justicia Especial para la Paz que eran percibidos como de izquierda radical y, por extensión, no neutrales en el proceso ${ }^{12}$.

${ }^{12}$ Frente a Diego García Sayán, de Perú, objetaban que había declarado fallos condenatorios contra las Fuerzas Militares y el Estado colombiano en tribunales internacionales; mientras que Juan E Méndez, de Argentina, había sido defensor de organizaciones terroristas peronistas; situaciones que para ellos ponían en entredicho su imparcialidad y objetividad.

Araucaria. Revista Iberoamericana de Filosofia, Política y Humanidades, año 20, nº 39. Primer semestre de 2018. Pp. 509-533. ISSN 1575-6823 e-ISSN 2340-2199 doi: 10.12795/araucaria.2018.i39.24 
El 19 de enero 2018 sectores de las Fuerzas Militares y de Policía enviaron una carta a la opinión pública, manifestando la inconformidad con los incumplimientos del Gobierno en la revisión y adaptación de sus recomendaciones en materia de justicia transicional. Destacando así que: "esta JEP se constituyó en un marco jurídico para beneficio exclusivo y preferente de las FARC, e instrumento útil para juzgar a sus contrapartes. El rechazo nacional, respecto a esta cuestionada figura, ha sido muy evidente. En ninguna circunstancia puede ser admisible que esta jurisdicción especial favorezca a un solo actor del conflicto" (ACORE, 2018)

Con respecto al fuero militar, hay que reconocer que éste ha sido objeto de revisión y reforma desde la llegada del Presidente Juan Manuel Santos, buscando "avanzar en la consolidación de una legislación encaminada a entregarle a la Fuerza Pública un marco jurídico claro para acometer su misión constitucional y reglas para la investigación y el juzgamiento de las conductas de sus miembros" (Observatorio de Derechos Humanos, 2015). De este modo, para las organizaciones de defensa de derechos humanos, el proyecto de reforma al fuero penal militar ha sido una preocupación por considerar que hay una interpretación del Derecho Internacional Humanitario que consideraría los daños a civiles como daños colaterales ${ }^{13}$. Mientras, desde otra perspectiva, esta vez la de la asociación de oficiales retirados ACORE, dicha reforma no brindaría ningún tipo de seguridad jurídica a los uniformados (El Espectador, $2015 \mathrm{f})$.

Estas actividades muestran una fuerte presión, o al menos articulación, de los intereses de las Fuerzas Militares en cuanto a la formulación del marco jurídico para el posconflicto, curiosamente, combinado con el proceso de fortalecimiento de la justicia penal militar y con una posición menos cuestionadora y retadora en materia de derechos humanos del Gobierno hacia las Fuerzas Militares. El presidente Juan Manuel Santos incluso se ha referido a la ley de amnistía y a la seguridad jurídica como importante frente a "los miembros de nuestra Fuerza Pública que, por alguna razón, cometieron alguna equivocación relacionada con el conflicto y por eso tengan problemas jurídicos" (El País, 2016).

\footnotetext{
${ }^{13}$ La Corte Interamericana de Derechos Humanos, es reiterativa en que es la justicia ordinaria la que debe hacerse cargo de estudiar las posibles violaciones de derechos humanos cometidas por militares, y no la justicia penal militar. En particular con respecto a las ejecuciones extrajudiciales, o muerte de civiles que eran presentados formalmente como miembros de los grupos armados ilegales dados de baja en combate, en particular porque el fuero militar se convertía en un obstáculo para el establecimiento de responsabilidades y genera impunidad. (CIDH 2015:84) La Organización Human Rights Watch publicó en su informe 2015 que hay altos oficiales del Ejército implicados en los falsos positivos, se menciona que la fiscalía tiene identificado 180 batallones y unidades tácticas que realizaron ejecuciones extrajudiciales entre 2002-2008, con un total de 5.137 miembros investigados por cerca de 4.475 víctimas de casos de falsos positivos en todo el país. (El Espectador,2015 h).
} 
De forma paralela a los cuestionamientos que se hace por parte de los militares a la JEP, muchos de ellos han solicitado al Gobierno acogerse a este sistema de justicia transicional. El 17 de marzo de 2017, el Ministro de Defensa solicitaba la libertad de 817 miembros de la fuerza pública que deseaban acogerse al sistema de justicia alternativa. En junio se sumaron otras 257 solicitudes para un total 1074 militares. Hay casos de militares que habían logrado preacuerdos con la Fiscalía y habían admitido cargos en materia de homicidio agravado, desaparición forzada y abuso de autoridad, solicitando por ello su inclusión en la JEP. La Fiscalía aceptó la inclusión en la JEP, aunque poniendo de manifiesto que respecto a delitos como la desaparición forzada no puede haber renuncia de persecución penal por tratarse de un crimen de lesa humanidad (Areiza, 2017).

A tal efecto, las Fuerzas Militares calculan que serán aproximadamente 8.000 militares y policías que se acogerán a la JEP. Las previsiones del General García Serna, subjefe de Estado Mayor Conjunto de Fortalecimiento Jurídico Institucional, reitera que al aplicar el Derecho Internacional Humanitario, la tasa de responsabilidad será cercana al $0.5 \%$, por la aplicación de los principios de humanidad, distinción, limitación y proporcionalidad, y que muchas de las acciones serán consideradas daños colaterales o daños incidentales.(Comando General de las Fuerzas Militares: 2017) Sin embargo, desde organismos como Human Rights Watch se tiene la expectativa que la Corte Constitucional pueda corregir elementos como la "responsabilidad de mando", por la que establece la responsabilidad de los comandantes militares en las acciones de sus subordinados, pues se considera, de acuerdo a lo planteado por el Gobierno, se iría en contra del Derecho Internacional y se terminaría eximiendo de responsabilidades a los altos mandos (Human Rights Watch, 2017; Ríos y Brocate, 2017b).

Otro de los temas álgidos para la interacción civil-militar se ha referido a las discusiones sobre la transformación de las Fuerzas Militares en el marco de un eventual posconflicto armado. Durante el proceso de negociación, los líderes guerrilleros buscaron incorporar el tema de los militares en las conversaciones, desatando una gran polémica. A tal efecto, uno de los miembros del equipo negociador de las FARC, "Jesús Santrich", miembro del Estado Mayor, afirmaba lo siguiente:

\footnotetext{
“Tenemos que hacer una depuración del Estado y de las Fuerzas Militares y de Policía, incluyendo los organismos de inteligencia que hayan estado comprometidos con procesos de victimización, atendiendo las conclusiones y recomendaciones de la 'Comisión de esclarecimiento y no repetición', concebida como una contribución al establecimiento de la verdad histórica y al reconocimiento de los derechos de las víctimas del conflicto" (RCN: 2015).
} 
En el marco del diseño institucional se han presentado, entre otros, algunos debates sobre tamaño, capacidad, recursos, y particularmente la redefinición del rol de las Fuerzas Militares en este nuevo contexto. Algunas de las dimensiones en las que se concentran las preocupaciones son, por ejemplo, el temor por perder la estabilidad laboral y los beneficios relacionados con el ejercicio de la vida militar y policial (Ramírez, 2016), además de los temas de justicia y verdad histórica, que podrán llevar a juzgamiento y reclamaciones a altos mandos. Otras de las preocupaciones más generalizadas en el estamento militar son la pérdida de posibles ingresos que se derivan una compleja red de negocios establecida por familiares o militares en retiro, en torno a aspectos logísticos y operativos propios del conflicto armado. También, algunos sectores de los militares aún profesan un profundo anticomunismo y consideran que de no existir el proceso de paz hubieran podido obtener una victoria militar en el marco del conflicto (León, 2014).

Uno de los puntos más sensibles, junto a todo lo anterior, se encuentra en si es necesario una reducción del número de la tropa, o si la reincorporación a la vida civil de los guerrilleros sería financiada con los recortes al presupuesto militar. Tanto el Presidente como los altos mandos han buscado hacer frente a esos temas, tratándolos como mera especulación. Sin embargo, desde 2011 se ha venido dando un proceso de reforma con la conformación de Comité de Revisión Estratégica e Innovación (CRE-I), que ha buscado el diseño de una fuerza adecuada y adaptada a los nuevos escenarios de la seguridad. Esto ha supuesto el inicio de la planeación del rediseño de las unidades de combate, vislumbrando escenarios de ubicación geográfica diferentes, sobre la base de una organización más flexible.

Para el año 2013 se introduce el concepto de la Fuerza Multimisión, ahondando en la idea de varios escenarios, esto es, una fuerza con capacidad de desarrollar diversas tareas, desde la seguridad y defensa convencional, hasta la asunción de escenarios de amenazas complejas. Este replanteamiento también conllevó una discusión sobre la doctrina, en la cual se revisó el concepto de guerra contrainsurgente y del anticomunismo, pues eran elementos que habían caracterizado la formación y entrenamiento de las Fuerzas Militares colombianas durante décadas.

En 2015 se establece el Plan Minerva, con el fin de mejorar el sistema de educación y doctrina del Ejército, así como el 'Plan Damasco y los manuales Piedra Angular, en donde se redefinen las concepciones estratégicas, operacionales y tácticas, buscando de este modo la revisión y adaptación para superar las operaciones irregulares propias del conflicto armado y avanzar hacia postulados de operaciones terrestres unificadas y en alineación con la doctrina de la Organización del Tratado del Atlántico Norte, OTAN (Rojas, 2017). 
En un nuevo contexto de seguridad se deberá dar una nueva orientación a las Fuerzas Militares, adecuando su doctrina, el equipamiento y preparación para afrontar las "nuevas" prioridades de seguridad, y que supone, de una u otra manera, tener que afrontar el debate de presupuesto, tamaño y actividades militares; una situación en la que le será muy difícil al Gobierno complacer a todas las partes involucradas. De hecho, al respecto algunos generales han planteado, entre otras opciones, la posibilidad de que la capacidad instalada de las Fuerzas Militares, su personal y equipamiento además de la estructura logística sea aprovechada en labores de construcción de infraestructura, instalación de bienes de uso público, transporte fluvial, incentivando así cadenas productivas que aumenten la cobertura de seguridad social, entre otras actividades (Colón, 2014).

El contexto de seguridad también ha variado en los años recientes, presentándose una reducción de la tasa de muertes violentas, que su para el 2007 era de 37.15 por cada 100.000 habitantes, el mismo indicador para el 2016 había descendido a 23.66. Las muertes asociadas al conflicto armado para las mimas fechas eran de 1.148 en 2007 y tan solo 196 para el año 2016, lo cual supone una disminución del $82 \%$ (Medicina Legal, 2016). Si bien esta situación no refleja una mejoría total de los indicadores en el país, por el contrario, los analistas de seguridad coinciden en hablar de una transformación de los factores de violencia, frente a lo cual bastaría recordar que, pese a las dimensiones y profundidad del conflicto armado interno, éste nunca fue la primera causa de mortalidad en el país.

Por un lado, están las consideraciones a corto y mediano plazo relacionadas con las garantías de seguridad para los guerrilleros en las zonas de concentración y las garantías a los procesos de desarme. En particular, porque adicionalmente a las armas entregadas (8.994 armas y 42.000 cargadores) se informó de la existencia de 998 caletas en diversas zonas del país que precisaron de la participación logística y de seguridad de las Fuerzas Militares a efectos de su incautación. En el mediano y largo plazo la situación de la seguridad de las zonas que habían sido tradicionalmente territorios de presencia de las FARC han comenzado a ser el aspecto más importante en cuanto a garantizar la estabilidad de las zonas y evitar la toma del espacio por parte de otros actores armados, lo cual se ha convertido en una amenaza y una urgencia prioritaria en la gestión de la seguridad y de la violencia en Colombia.

Desde el 2014 se ha venido hablando también de los conceptos de paz territorial y presencia integral del Estado en el territorio (Ríos, 2018; Cairo et al., 2018). No sólo por la idea de que es necesario que el Estado garantice las condiciones mínimas para el ejercicio de los derechos de los ciudadanos, se elimine la violencia estructural y se haga una presencia efectiva en el territorio. Este desafío es aún más relevante, pues no puede pasarse por alto el hecho de 
que la guerrilla de las FARC tenía presencia en alrededor de 242 municipios. Una extensión que con el Acuerdo se redujo a 26 zonas veredales que implicaba la dejación del 90\% del territorio libre. La Fundación Paz y Reconciliación ha caracterizado estos territorios en cinco tipologías: aquellos con presencia del ELN, los que tienen presencia de bandas criminales, los copados por la delincuencia común, las áreas de disidencias de las FARC, y finalmente, aquellos que recuperarán la presencia íntegra del Estado (Fundación Paz y Reconciliación: 2017).

Las Fuerzas Militares tienen el reto de hacer presencia en esos territorios dejados por las FARC, por tanto, no solo para hacer frente a los viejos desafíos derivados de la presencia de otros actores armados, sino también para afrontar las nuevas dinámicas de inseguridad. Las Fuerzas deberán ser mucho más visibles y más eficientes en el enfrentamiento a las bandas criminales, las nuevas formas de paramilitarismo, la producción y tráfico de narcóticos y la minería ilegal. Las bandas criminales o las mutaciones de las estructuras paramilitares han incrementado su presencia en diversos municipios aparejados de los delitos de homicidio, extorsión y hurto. La trama de amenazas se transpone en algunas áreas de manera que estas bandas han establecido nexos con disidencias o con miembros de la guerrilla del ELN. De ahí que el conflicto se aleje de las causas políticas y se revista de criminalidad. Así, adecuar el funcionamiento de la fuerza pública a estas nuevas organizaciones se erige como un reto importante que deberá ser atendido de forma prioritaria. Curiosamente, en el contexto de exigir resultados, se retoma la discusión sobre el tamaño y capacidad enorme que tendrían ya instaladas las Fuerzas Militares y de Policía y el bajo nivel de eficiencia en el control de las amenazas de seguridad.

Tanto las Fuerzas Militares como la Policía han sido los agentes principales en materia de lucha contra el narcotráfico. El Acuerdo de Paz supuso el diseño de una nueva estrategia en materia de sustitución de cultivos a través del Programa Nacional Integral de Sustitución de Cultivos de Uso Ilícito (PNIS). Ello, con subsidios temporales para incentivar la erradicación manual, lo cual se ha orientado igualmente hacia la terminación de las aproximaciones de sustitución forzada y fumigaciones. En este sentido, el accionar militar ha tenido que transformarse para apoyar a las agrupaciones de erradicación. Sin embargo, esta política también ha tenido sus detractores, en cuanto que consideran que el diseño brinda incentivos para la expansión de cultivos, al disponer de retribuciones económicas en zonas rurales en donde no se ha presentado como tal una renovación de los modelos de producción o mejoras en las condiciones de empleo y la producción en sectores legales de la economía.

A todo lo anterior habrá que añadir la importancia de algunos temas que en los últimos años se han consolidado como las principales amenazas para la seguridad dentro del escenario de posconflicto armado colombiano. De un 
lado, está la minería ilegal, la cual se convierte en uno de los temas que debería ser prioritario, pues la mayor demanda de oro ha llevado consigo el aumento de las explotaciones ilegales hasta el punto de que:

"el 63\% de la explotación minera no es legal y de ésta una parte importante es abiertamente criminal, es decir, ligada a organizaciones del crimen organizado o a las guerrillas. La hipótesis que se mueve ahora entre los expertos es que la principal fuente de financiación de estas organizaciones es la minería ilegal y no el narcotráfico" (Valencia:2017).

De otro lado, la violencia homicida en el contexto del posacuerdo se está dirigiendo preocupantemente hacia líderes de restitución de tierras, líderes sociales, miembros de escuadrones de sustitución de cultivos y desmovilizados. Esto lleva a identificar la victimización de civiles con un elemento de cercanía o proximidad al proceso de paz. En esa dirección, las Fuerzas Militares deberán convertirse en el garante por excelencia de la integridad de estos sectores sociales, pues el aumento significativo de estas amenazas y homicidios muestra una lenta respuesta por parte de los actores estatales, tanto políticos como militares, particularmente, porque los indicios y amenazas, aunque son dados a conocer antes de que ocurran los asesinatos, no se logra o no se hace ningún tipo de intervención o prevención.

\section{Conclusiones}

Las Fuerzas Militares colombianas han tenido en el conflicto interno un espacio de autonomía importante que ha permitido reducir su potencial de intervención en la política. Como institución, hacen reivindicación a una larga historia y tradición por el respeto a las autoridades civiles y los procesos democráticos. Sin embargo, en algunos momentos han sido los líderes civiles quienes han movilizado a las Fuerzas Militares con objetivos claramente políticos.

En los años cincuenta se promovió el único Gobierno militar del siglo XX, el cual duró poco y sucumbió a las mismas presiones de los partidos políticos que percibieron la participación directa de los militares en el Gobierno como una amenaza para su estabilidad. Los procesos de negociación del conflicto armado con las guerrillas han sido los elementos de tensión civil militar más recurrentes. Las inconformidades con los procesos de paz han sido verbalizadas en algunas ocasiones en lo que se conoce como "ruidos de sables", en los cuales la oficialidad de las Fuerzas Militares da a conocer los puntos de desacuerdo con el manejo de la negociación. Sin embargo, estas experiencias han terminado con la reafirmación de la autoridad presidencial como Comandante en Jefe de las Fuerzas Militares y el llamado a calificar servicios a los militares inconformes. 
El proceso de paz del Gobierno de Juan Manuel Santos con la guerrilla de las FARC ha producido importantes manifestaciones de desacuerdo y cuestionamientos por parte de las Fuerzas Militares, además de tensiones no evidenciadas en procesos de negociación anteriores. Dos aspectos pueden estar relacionados con el mayor activismo y presencia de las Fuerzas Militares al respecto. Primero, las Fuerzas son hoy más grandes y equipadas que en décadas anteriores. Segundo, aquéllas venían de aplicar una estrategia ofensiva con las guerrillas que había dejado consigo importantes resultados operacionales. Estos dos aspectos hacían, en perspectiva de los militares y algunos sectores políticos, viable y predecible la derrota militar de las FARC, por lo cual el proceso de negociaciones era percibido como un error estratégico que permitiría la reorganización y fortalecimiento de las guerrillas. Asimismo, este proceso de paz introdujo como novedad la presencia de negociadores provenientes de la fuerza pública en representación de los intereses de los militares y policías, aparte de destacar el valor de militares activos en el proceso de discusión de aspectos técnicos del desarme, movilización y reincorporación.

La polarización política desarrollada en torno al proceso de paz, las negociaciones y el Acuerdo han generado espacios para vincular y activar políticamente a los sectores militares. La oposición al Gobierno de Santos, liderada por el expresidente Álvaro Uribe, ha sido muy eficiente a la hora de canalizar y movilizar supuestos descontentos del sector con el proceso, al tiempo que las organizaciones que representan a los militares y policías en retiro han aumentado su visibilidad, participando en las discusiones y análisis de impacto del proceso de paz sobre sus miembros.

Más delicado que la negociación y el diseño del Acuerdo será la fase de la implementación, pues es dónde se verá la verdadera dimensión y profundidad de los retos que tiene ante sí la relación civil-militar en Colombia, además de la capacidad institucional de las Fuerzas Militares de transformarse de forma sustancial en un corto periodo de tiempo. Sin duda, estas Fuerzas Militares resultan unos actores estratégicos para lograr el Acuerdo de paz, pero ante todo son más importantes en la construcción de las condiciones para una paz duradera y el postconflicto que ha de implementarse en los próximos años en Colombia. Un intrincado escenario en el que la justicia transicional y la construcción de la memoria y la verdad en el país podrá de manifiesto muchas acciones cuestionables del pasado frente a todos los actores involucrados en la violencia, incluidos los actores estatales, y que serán temas de alta sensibilidad para la interacción civil-militar en los años próximos. 


\section{Referencias bibliográficas:}

Asociación Colombiana de Oficiales en Retiro de las Fuerzas Militares (ACORE) (2018). Seguridad Jurídica Institucional: La JEP Un salto al vacio para la Fuerza Pública Carta Abierta a la Opinión Pública. http:// www.acore.org.co/noticias/carta-abierta-la-opinion-publica-2/

Asociación Colombiana de Oficiales en Retiro de las Fuerzas Militares (ACORE) (2016). Militares en retiro ratifican respaldo a Justicia Transicional del proceso de paz con Farc. http://www.acore.org.co/noticias/militaresretiro-ratifican-respaldo-justicia-transicional-del-proceso-paz-farc/

Angarita, P. (2011). Seguridad democrática lo invisible de un régimen político y económico. Medellín: Siglo del Hombre

Atehortúa, L. (2010). "El golpe de Rojas y el poder de los militares". FOLIOS Segunda época, 31, 33-48.

Areiza, R. (2017). "A justicia transicional militares implicados en falso positivo". La Nación. http://www.lanacion.com.co/2017/06/25/justiciatransicional-militares-implicados-falso-positivo/

Avilés, W. (2006). Global Capitalism, Democracy, and Civil-Military Relations in Colombia. Nueva York: Suni.

Cairo, H. et al. (2018). "Territorial Peace": The Emergence of a Concept in Colombia's Peace Negotiation". Geopolitics. En prensa: http://www. tandfonline.com/doi/full/10.1080/14650045.2018.1425110

Corte IDH (2015). Informe No. 41/15, Casos 12.335, 12. 336, 12. 757, 12.711. Fondo. Gustavo Giraldo Villamizar Durán y otros. Colombia. 28 de julio de 2015. http://www.oas.org/es/cidh/decisiones/corte/2016/12335FondoEs. pdf

Colón, R. (2014). La transición y los militares del posconflicto. https://www. las2orillas.co/la-transicion-y-los-militares-del-posconflicto/ La transición y los militares del posconflicto

Comando General de las Fuerzas Militares (2017). Justicia Especial para la Paz para la Fuerza Pública. http://www.cgfm.mil.co/2017/09/18/justiciaespecial-la-paz-segun-las-fuerzas-militares/

Correa, H. (2006). Hablan los generales: las grandes batallas del conflicto colombiano contadas por sus protagonistas. Bogotá: Norma.

Cuellar, J. (2017). ¿Inconformismo en los cuarteles? Los miedos de los militares en la JEP. https://colombia2020.elespectador.com/pais/los-miedos-delos-militares-en-la-jep

Dávila, A. (2017). "Ejército regular, conflictos irregulares: la institución militar en los últimos quince años". Working Paper 4, Paz Pública: programa de Estudios sobre Seguridad Justicia y Violencia. Bogotá: Universidad de los Andes. 
El Colombiano (2017). "Militares y justicia transicional". http://www. elcolombiano.com/opinion/editoriales/militares-y-justicia-transicionalCH5988949

El Espectador (2015). “Aprobada en último debate reforma al Fuero Penal Militar". http://www.elespectador.com/noticias/politica/aprobada-ultimodebate-reforma-al-fuero-penal-militar-articulo-565574

El País (2016). "Esquema de Justicia transicional para militares está listo". http:// www.elpais.com.co/proceso-de-paz/esquema-de-justicia-transicionalpara-militares-esta-listo-santos.html

Fernández de Soto, G. (2004). La ilusión posible: un testimonio sobre la política exterior colombiana. Bogotá: Norma.

Fundación Paz y Reconciliación (2017). "En qué están los territorios que dejan las Farc; estado de las zonas de concentración y las agresiones a líderes sociales". http://www.pares.com.co/paz-y-posconflicto/en-que-estan-losterritorios-que-dejan-las-farc/

Global Fire Power Index (2017). Military Strength Ranking https://www. globalfirepower.com/countries-listing.asp

Gómez Gallego J. et. al. (2010). Informe final de la Comisión de la Verdad sobre los hechos el Palacio de Justicia. Bogotá: Universidad del Rosario.

González, F. y Posada, E. (2001). "Criminalidad, Violencia y Gasto Público en Defensa, Justicia y Seguridad". Colombia Revista de Economía Institucional, 3(4), 78-102.

Hartlyn, J. (1984). "Military Governments and the Transition to Civilian Rule: The Colombian Experience of 1957-1958". Journal of Interamerican Studies and World Affairs, 26(2), 245-281.

Human Rights Watch (2017). "Colombia: Oportunidad para corregir graves defectos de la justicia transicional". https://www.hrw.org/es/ news/2017/07/06/colombia-oportunidad-para-corregir-graves-defectosde-la-justicia-transicional

Leal, F. (1994). El oficio de la Guerra: la Seguridad Nacional en Colombia. Bogotá: 1994.

Leal, F. (1995). En Busca de la Estabilidad Perdida: Actores políticos y sociales en los años noventa. Bogotá: IEPRI.

León, J. (2014). "Los cuatro temores de los militares frente al proceso de paz". http://lasillavacia.com/historia/historia-militares-juanita-49005\#sthash. jOgeXEWA.dpuf

Medicina Legal (2016). "Datos para la vida". www.Medicinalegal.gov.co/ documents/88730/4023454/forensics+2016+-+datos+para+la+vida.pdf

Neira, A. (2014). "Los rumores que calaron en las Fuerzas Armadas". http:// www.semana.com/nacion/elecciones-2014/articulo/los-rumores-quecalaron-en-las-fuerzas-armadas/390383-3 
Pizarro, E. (1989). "Profesionalización militar en Colombia: los regímenes militares 1953-1958". Análisis Político, 3, 4-37.

Premo, D. (1992). "The Politics of civilian rule in Colombia". En C. Danopoulos (Ed.). From Military to Civilian Rule. Nueva York: Routledge.

Ramírez, N. (2016). Proceso de Paz en Colombia. El Presidente del Cuerpo de Generales y Almirantes en Retiro, nos da su opinión. https://www. fuerzasmilitares.org/proceso-de-paz/6962-cga-proceso-de-paz.html

RCN (2015). "Las Farc dicen que se deben "depurar" las Fuerzas Militares". http://www.noticiasren.com/nacional-pais/las-farc-dicen-se-debendepurar-las-fuerzas-militares

Restrepo, J. D. (2014). "Militares hacen lo que les dé la gana". http:// www.semana.com/opinion/articulo/militares-hacen-lo-que-les-de-lagana/376431-3

Revista Semana (2015a). "El informe que demuestra la caída en los operativos militares". http://www.semana.com/nacion/articulo/dialogos-de-paz-elinforme-que-demuestra-la-caida-en-los-operativos-militares/420716-3

Revista Semana (2015b). "El mal momento que vivió Santos en la carrera por los militares". http:/www.semana.com/nacion/articulo/santos-recibesilbatina-en-carrera-por-militares-caidos/424755-3

Revista Semana (2014a). "Militares quieren justicia alternativa".

http://www.semana.com/nacion/articulo/militares-presentaran-propuestas-lamesa-de-la-habana/399842-3

Revista Semana (2014b), "Militares en La Habana”. http://www.semana.com/ nacion/articulo/militares-en-la-habana/400112-3

Revista Semana (2006). "Esto dijo Belisario". http://www.semana.com/wf InfoArticulo.aspx? IdArt=91832-

Ríos, J. (2018). "Transformations in the narrative of the Colombian Public Force within the framework of the armed posconflict: from military victory to territorial peace". Revista UNISCI, 47, 219-234.

Ríos, J. (2017) Breve historia del conflicto armado en Colombia. Madrid: La Catarata

Ríos, J. y Brocate, R. (2017). "Violencia sexual como crimen de lesa humanidad: los casos de Guatemala y Perú". CIDOB Revista d'Afers Internacionals, $117,79-99$.

Ríos, J. (2015). "Del Caguán a La Habana. Los diálogos de paz con las FARC en Colombia: una cuestión de correlación de fuerzas". Revista de Estudios en Seguridad Internacional, 1(1), 63-83.

Rojas, P. J. (2017). "Doctrina Damasco: eje articulador de la segunda reforma del Ejército Nacional de Colombia". Revista Científica, General José María Cordova, 15(19), 95-119. 
Sánchez, R. (2010). "A los 25 años de los Crímenes en el Palacio de Justicia". Revista Espacio Crítico, 13, 105- 112.

Téllez, E. y A. Sánchez. (2003). Ruido de Sables. Bogotá: Planeta.

SIPRI (2017). Military expenditure by country as percentage of government spending, 1988-2016. Estocolmo: SIPRI.

Torres, C. (2000). Fuerzas Armadas y Seguridad Nacional. Bogotá: Planeta.

Torrijos, V. et al (2017). Farc: ¿derrota militar y victoria política. Bogotá: Oveja Negra.

Uprimny, R. y Vargas, A. (1990). "La palabra y la sangre: violencia, legalidad y guerra sucia". En G. Palacio (Comp.). La irrupción del paraestado. Ensayos sobre la crisis colombiana. Bogotá: ISLA.

Valencia, L. (2014). "El miedo de los militares". http:/www.semana.com/ opinion/articulo/leon-valencia-el-miedo-de-los-militares/378072-3

Valencia, L. (2017). "Las Bandas Criminales y el postconflicto". www.pares. com.co/paz-y-posconflicto/las-bandas-criminales-y-el-postconflicto

Vanguardia Liberal (2017). "Solicitan la libertad de 817 policías y militares". http://www.vanguardia.com/colombia/392254-solicitan-la-libertad-de817-policias-y-militares

Valencia, A. (1992). Testimonio de una Época. Bogotá: Planeta.

Vargas, A. (2002). Las Fuerzas Armadas en el conflicto colombiano: antecedentes y perspectivas. Bogotá: Intermedio.

Vargas, A. (2003). "Nueva prospectiva para la paz de Colombia". Convergencia, $31,59-87$.

Zuleta, F. (2015). “Otro sapo grande”. http://www.elespectador.com/opinion/ otro-sapo---grande 
